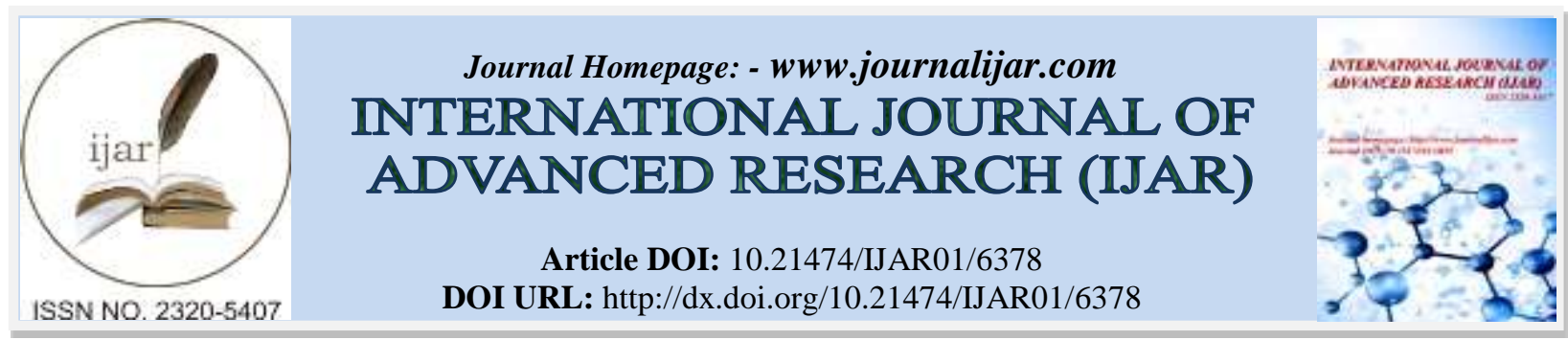

RESEARCH ARTICLE

\title{
UMBILICAL CORD RESTRUCTURE: AN UNCOMMON CAUSE OF INTRAUTERINE FETAL DEATH.
}

\section{Fatima el mangoub, Soumaya Berrada, Safae Ihssane, Ihsasane Hakimi, Moulay Mehdi Hassani, Jaouad Kouach and Driss Rahhali Moussaoui.}

1. Military and Training Hospital Mohammed V.

2. Faculty of Medicine and Pharmacy of Rabat, Rabat, Morocco.

\section{Manuscript Info}

Manuscript History

Received: 22 November 2017

Final Accepted: 24 December 2017

Published: January 2018

Key words:-

Umbilical cord stricture, umbilical cord, intrauterine fetal death, , intrauterine growth restriction.

\section{Abstract}

Umbilical cord stricture (UCS) refers to an umbilical cord (UC) with a strict zone. its link with the intrauterine fetal death (IUFD) has been established. A 26-year-old woman, primigravida, was admitted for IUFD. Post mortem examination demonstrated a macerated female infant weighing $440 \mathrm{~g}$. The placenta weighed $320 \mathrm{~g}$. The umbilical cord was $47 \mathrm{~cm}$ length, $10 \mathrm{~mm}$ diameter, normally coiled with 14 coils, and presents a stricture at the fetal insertion site which was pale, $2 \mathrm{~mm}$ diameter and $7 \mathrm{~mm}$ length. There was no other macroscopic anomaly in the fetus or the placenta.The IUFD was attributed to the UCS. Warnings must be given about performing an ultrasonographic evaluation of the UC in case of IUGR and a detailed examination of the UC after delivery in case of IUFD ou IUGR. Also, patient with a previous IUFD or even IUGR attributed to UCS must be informed about the risk of recurrence in her future pregnancies, and the UC must be evaluated by ultrasonography following even minor maternal complaints.

Copy Right, IJAR, 2018,. All rights reserved.

\section{Introduction:-}

Umbilical cord stricture (UCS) also named umbilical cord constriction, umbilical cord coarctation, umbilical cord stenosis, refers to an umbilical cord with a strict zone but has still no widely accepted quantitative definition. Even this entity is rare with unknown rate of occurrence $(1,2)$ its link with the intrauterine fetal death IUFD has been established (1,3-5). But many others aspects of this condition remain unclear including its etiologies, pathogenesis, the risk of occurrence and the management of subsequent pregnancies $(1,3,5)$.

\section{Case Presentation:-}

A 26-year-old woman, primigravida, presented for the first time to our department with abdominal pain a few hours. Her medical, surgical and family histories were unremarkable. She had no consanguinity with her husband. She presented with no document prenatal care, the exact gestational age is unknown, but she said she is pregnant in the seventh month and that her pregnancy progressed normally until two months ago when she had a medical examination and an obstetric ultasonography. The examination revealed uterine contractions, a fundal height of 22 $\mathrm{cm}$, short and two fingers dilated cervix, an unruptured amniotic membrane and a fetus in the breech presentation. Fetal cardiac sounds were not found by the obstetric stethoscope. The ultrasonography showed intrauterine fetal death, with femoral length of $40 \mathrm{~mm}$ consistent with 22 to 24 weeks gestation, an overlapping skull bones and severe oligohydramnios. The patient denied a rupture of the amniotic membranes. The patient was admitted and expelled 
five hours later a nonviable infant together with the placenta.The external fetal examination demonstrated a macerated female infant weighing $440 \mathrm{~g}$. The placenta weighed $320 \mathrm{~g}$. The umbilical cord was $47 \mathrm{~cm} \mathrm{length,} 10 \mathrm{~mm}$ diameter, normally coiled with 14 coils, and presents a stricture at the fetal insertion site which was pale, 2 mm diameter and $7 \mathrm{~mm}$ length (Figure 1). There was no other macroscopic anomaly in the fetus or the placenta.The IUFD was attributed to the UCS. No autopsy or histopathological examination was performed. Postpartum period was uneventful, and our patient was discharged on first postpartum day. She was advised of the risk of recurrence and the fetal close surveillance during her next pregnancy.

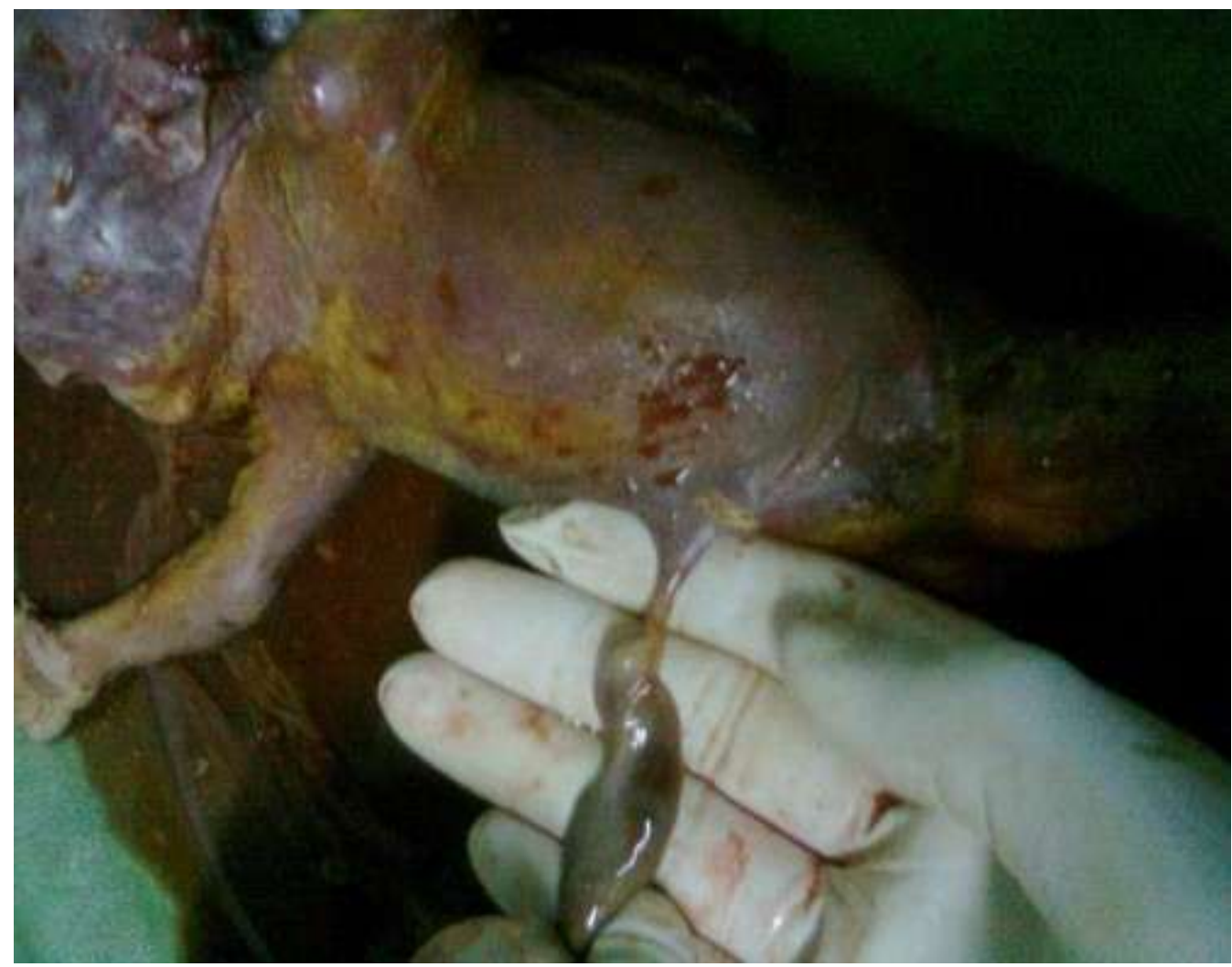

Figure 1:- Post mortem examinationshowing anUCSatthefetal insertionsitewhichwas pale, $2 \mathrm{mmdiameterand} 7 \mathrm{~mm}$ length.

\section{Discussion:-}

The reported frequency of UCS is very varied and ranges from $6 \%$ to $20 \%$ of all perinatal autopsies (3). For the most of the authors it has no predilection for race, parity, gestational age, or fetal sex (2). It is easy to recognize on gross examination 3). It can occur anywhere along the UC length, but it occurs most commonly at the extreme fetal end $(1,2,6)$. It can be independent or associated with other cord anomalies,such as hypocoiling, hypercoiling, torsion, thinning, or excessive length $(1,3,6)$. On the microscopic examination there is a lack of Wharton's jelly and an abundance of fibrosis at the site of the stricture, vessels that are compressed or narrowed, occasionally with thrombosis (1).The genetic or environmental causes remain unknown (2,3). Several theories explaining the pathogenesis of this condition have been considered, but actually the theory of a primary deficiency of Wharton's jelly with secondary compression or obstruction is the most accepted (2,3). In fact, Wharton's jelly is known to protect the umbilical vessels. Without Wharton's jelly, vessels tend to twist or be compressed easily and stricture can develop, followed by fetal complications $(1,4)$. The causal link UCS and IUFD has long been established $(1,3-$ 5). Most IUFD attributed to UCS are seen at 6-month to 9-month of gestation (1,6 ), but UCS occurs early in gestation, while the fetus is still small $(2,4)$. The narrowing of the blood vessels within the UCS area causes a decrease in the blood flow to the fetus. As the fetus grows, decreased umbilical blood flow fails to meet the demands of the developing fetus, the fetus develops IUGR, becomes hypoxic and then acidotic, and IUFD follows (1,2,4). Even the UCS has been traditionally considered a sporadic anomaly, the risk of recurrence is undetermined in the available data, it varies from very low to increased risk (1,3-5). Because of possiblelegal implications, patient with a 
previous IUFD attributed to UCS must be informed about the risk of recurrence in her future pregnancies (5). Such pregnancies should be properly counseled and the fetus nearly followed up $(1,4)$. The given information must precise the possibility of an early intervention with possible fetal morbidities as a consequence of preterm delivery (1). It may be prudent to evaluate the umbilical cord following even minor maternal complaints especially a sudden change in fetal activity $(2,5)$. A careful Umbilical cord ultrasonography, particularly at the fetal end, and a Doppler flow velocimetry of the UC vessels should follow (2).

\section{References:-}

1. French AE, Gregg VH, Newberry Y, Parsons T. Umbilical cord stricture: a cause of recurrent fetal death. Obstetgynecol 2005;105:1235-9. DOI: 10.1097/01.AOG.0000159041.55845.f7

2. Wahl C, Masliah E. Umbilical cord stricture in a 21-week fetus. J Perinatol 2004;24:48-49DOI: 10.1038/sj.jp.7211015

3. Rodriguez JI, Marino-Enriquez A, Suarez-Aguado J, Lapunzina P. Umbilical cord stricture is not a genetic anomaly: a study in twins. Pediatrdevpathol. 2008 Sep-Oct;11(5):363-9. DOI: 10.2350/07-08-0329.1

4. Tan SJ, Chen CH, Wu GJ, Chen WH, Chang CC. Fetal demise by umbilical cord around Abdomen and stricture. Arch gynecolobstet 2010;281:137e9 DOI: 10.1007/s00404-009-1081-5

5. Collins JH. Umbilical cord accidents and legal implications. Seminfetalneonatal Med 2014;19:285-9 DOI: 10.1016/j.siny.2014.08.008

6. Pinar H, Carpenter M. Placenta and umbilical cord abnormalities seen with stillbirth. Clin Obstet Gynecol 2010;53:656-72 DOI: 10.1097/GRF.0b013e3181eb68fe. 